\title{
What Master Teachers Do: A Case Study of Planning, Facilitating, Role Modelling and Developing Materials
}

\author{
Noraini Ibrahim ${ }^{1}$, Azliza Haniem Abdul Aziz ${ }^{2} \&$ Radha M. K. Nambiar ${ }^{1}$ \\ ${ }^{1}$ School of Language Studies and Linguistics, Faculty of Scoail Sciences and Humanities, Universiti \\ Kebangsaan Malaysia, Selangor, Malaysia \\ ${ }^{2}$ Ministry of Education, Malaysia \\ Correspondence: Noraini Ibrahim, School of Language Studies and Linguistics, Faculty of Social Sciences and \\ Humanities, Universiti Kebangsaan Malaysia, 43600 UKM Bangi, Selangor, Malaysia. Tel: 60-389-215-375. \\ E-mail: nib@ukm.my
}

Received: February 7, 2013 Accepted: March 25, 2013 Online Published: May 13, 2013

doi:10.5539/ies.v6n6p86 URL: http://dx.doi.org/10.5539/ies.v6n6p86

\begin{abstract}
Teaching is the foundation of our educational system. As such teachers are privileged with the responsibility of nurturing the young and inadvertently, shaping the future. To this end, the Malaysian government is fully cognizant that our future is dependent on the development of a highly skilled and innovative workforce serving as the critical enabling factor for economic growth. Hence, several initiatives were introduced in the education sector, and one of them is the Skim Guru Cemerlang or Excellent Teacher Scheme. The premise is that these Master Teachers comprise the crème de la crème of the Malaysian teaching profession and their teaching practices will be different from the general, non-master teachers. This paper reports on a study that investigated the best practices of three Master Teachers of the English language in two secondary schools in Malaysia. As these master teachers were selected by the Ministry of Education based on very stringent prerequisites, the question is, how different are master teachers from 'normal' teachers? Further, in terms of classroom discourse, how is this difference manifested? Based on a research design that incorporated ethnography and applied discourse analysis, three master teachers were selected and observed during formal teaching hours as well as outside the classroom. Interviews were then conducted with the teachers as well as other stakeholders, namely the students and school administrators to triangulate the data. Additionally, documents were then collected and perused. The data went through a four-step analysis. Several key findings will then be revealed and the paper ends with suggestions for further work.
\end{abstract}

Keywords: facilitating, improvising, master teachers, managing, planning

\section{Introduction}

Teaching is the foundation of our educational system. As such teachers are privileged with the responsibility of nurturing the young and inadvertently, shaping the future. To this end, the Malaysian government is fully cognizant that our future is dependent on the development of a highly skilled and innovative workforce serving as the critical enabling factor for economic growth. To meet this target, the government is also fully aware of the quality of the delivery system, namely the teachers. The preliminary findings of the Malaysian Educational Blueprint on Shift 4: Transform teaching into a profession of choice states:

International research shows that teacher quality is the most significant school-based factor in determining student outcomes. The quality of a system cannot exceed the quality of its teachers. While there are certainly many excellent teachers in the Malaysian education system, a 2011 research study found that only $50 \%$ of lessons are being delivered in an effective manner. This means that the lessons did not sufficiently engage students, and followed a more passive, lecture format of content delivery. These lessons focused on achieving surface-level content understanding, instead of higher-order thinking skills. This statistic is particularly challenging as an estimated $60 \%$ of today's teachers will still be teaching in 20 years' time.

The Blueprint has rightfully pointed out just how alarming and challenging the teaching scenario is, notably with reference to the 2011 study and its impact on our students 'ability. To improve on teacher quality, the Blueprint has outlined more selective intake criteria. But for the present and the "estimated $60 \%$ who will still be teaching 
in the next 20 years" Shift 4 of the blueprint has also included pathways for teachers to achieve excellence through "Enhance pathways for teachers into leadership, master teaching and subject specialist roles by 2016."

Master teaching or master teachers is a scheme that was introduced in 1993. According to the Ministry's guidelines published in 2007, an applicant must have the right personality, possess knowledge and skills, be able to expand the learning outcomes of students (work culture), possess excellent communication skills, exhibit potential (visionary, proactive with initiative), and finally, to be able to contribute to the nation's development in the field of education. It is apparent that a wholesome, global player is required. Apart from the stated requirements, an applicant must satisfy several technical requirements that include an excellent prior service record, teaching her area of expertise and being sanctioned by her superiors (Hapidah Mohamed, 2001). While the Malaysian definition of master teachers encompass several pertinent areas, an earlier study by Coladarci (1991) shows that this concept was already being grappled with by educators and administrators alike in the United States. The issue then was how different are 'master teachers' from 'effective teachers'. The researcher had reviewed the works done that attempted to provide a type of mechanism to identify master teachers and he came to the conclusion that, " 'Master teacher' connotes sense of privilege and status - a title conferred upon teachers who have demonstrated a role beyond competence.....Effectiveness, in short, is a liberal criterion for identifying master teachers" (1991, p. 5). To a certain extent, the stringent prerequisites deemed of Malaysian master teachers are parallel to Coladarci's ideals.

While the premise of these Master Teachers is that they comprise the crème de la crème of the Malaysian teaching profession, the expectations will rightly be that their teaching practices ought to be different from the general, non-master teachers. The issue is, is this true? Hence this paper attempts to answer the following question: Are master teachers different from 'normal' teachers? If they are, how is the difference manifested in classroom practice?

\subsection{English Language Teaching in Malaysia}

English language teaching in Malaysia has undergone many changes over the last five decades reflecting the changes in administrative policies emanating from issues of nationism and nationalism post 1957 Independence from the British. Gill, Nambiar, Noraini and Tan (2011), in the tenth chapter of Globalization of Language and Culture in Asia, offer a lucid account of the concerns that led to changes in language policy in education, albeit up to 2011. Such concerns include the formation of a new world order, of the demands of the information technology revolution, of education systems producing global citizens equipped for the knowledge economy and more importantly of language as economic commodities and not mere linguistic capital. In 2003, a bold move was initiated notably the teaching of Mathematics and Science in the English language amidst support and criticisms. The policy was however abolished in 2012. In the Malaysian school system, the English language remains as a subject to be learned, but not a pre-requisite to pass. Hence, it is not surprising that there is abundant literature on the marginalization of the English language that has led to a decline in proficiency and competence among school children.

To arrest the decline in the proficiency of English, the Malaysia Education Blueprint 2013-2025, has carved out Shift 2 with the objective to "Ensure every child is proficient in Bahasa Malaysia and English language". A two-pronged strategy aimed at the students and the teacher was also outlined. Hence, by the end of Form Five, 70\% of the students will score a credit in SPM English (against Cambridge 1119) standards. However, this is being implemented now and it is against this backdrop of deteriorating standards that the master teachers of this study are investigated.

\subsection{Master Teachers in Malaysia}

The literature on master teachers in Malaysia is still in infancy. Marlini (2008), is a qualitative study that investigated how master teachers teach Mathematics. Using only three interview (one face-to-face and two by emails) supported by an examination of documents, Marlini found that these skilled and qualified teachers their teaching (Tsui, 2003), fostered engagement with their students, and planned their classes. A possible weakness of the study is a lack of classroom observation as a tool of inquiry that would provide a thick description of the findings. On the other hand, $\mathrm{Ng}$ (2009) investigated how master teachers created thinking classrooms through a case study of four teachers from different science disciplines. In this study, questionnaires, prolonged observations and interviews were employed as tools of enquiry. Her case subjects were also given a notebook to $\log$ in their reflections, thought and comments. In analyzing the data, a multiple comparative method was employed. The findings showed that despite all these science teachers are master teachers, their practices in developing the thinking classroom were not the same. The differences are interestingly as they are driven by the subjects' personal beliefs and approaches to teaching. 
Lyla (1997) focused on two master teachers and their pedagogical practices in the ESL (English as a second language) reading class. She investigated into the beliefs, decisions and practices of her subjects. As Lyla employed a qualitative research design that alludes to observe and collect', she was able to get a thick description of what happened in the classroom as $\mathrm{Ng}$ (2009) did. In both cases, the findings showed contradictions between the teachers' beliefs and their classroom behavior in relation to the learners and the role of teachers. On a different vein, Hapidah (2001) employed a quantitative study into the master teachers' cognitive processes and their impact on teaching. Here, she formulated a Thinking Model for master teachers, which among others showed that years of teaching, subject specialization and experience are not strong indicators of master teachers. Instead, the context in which the learning takes place (the ecology of the school, students, educational system, parental engagement and the like) influence the master teachers. Hapidah's findings are interesting in light of Coladarci's study.

As a final note to this section, it is pertinent to see that in some ways, the criteria imposed on applicant to be master teachers bear some semblance to the Dreyfus and Dreyfus (1986) criteria of experts as well as to Tsui's (2003) expertise in the classroom. The gap in knowledge here is on master teachers of the English language and how they cope in an environment that may not be that conducive to their goal.

\subsection{Ethnography and Discourse Analysis}

This study is motivated by a curiosity of what actually is going on in the classroom of master teachers. It is motivated by the belief that "the language used by teachers and students in classrooms determines what is learned and how learning takes place" (Wilkinson and Silliman (2000). Hence, In order to capture the actual language used, in-situ observations were carried out to yield useful and valuable insights into the best practices of language teaching. To this end, this study takes a qualitative approach, employing ethnographic tools of inquiry, namely that of 'ask, observe and collect', though not necessarily in that order. The second researcher for this study is a master teacher and as she is familiar with the culture of the context, she collected the data through non-participant observation. It is thus not the case of an outsider trying to make meaning of the context as in all other ethnographic studies as shown by Geertz (1973), Denzin (1978), Creswell (2008), to name a few. Further, as the ethnographic tradition does not traditionally record and analyze verbatim transactions, it is deemed necessary to locate an approach to discourse analysis that would do so. Hence the applied discourse analysis approach undertaken is conversation analysis a position supported by Atkinson, Okada, and Talmy (2011).

In relation to features of classroom discourse, this study alludes to the works done by Walsh (2006), Sinclair and Brazil (1982) and Mehan (1979). Walsh (2006) enquired into teachers 'classroom discourse in smaller units and focused on communication patterns between teachers and students, elicitation techniques, repairs and modification of speech. Sinclair and Brazil (1982) showed that the content of the lessons, the organization of those lessons s well as classroom discipline are features that need to be paid attention to as sell. Finally, Mehan (1979) in one of the earlier studies, enquired into the teaching structure. However, there has yet to be a qualitative study that enquires into the discourse of master teachers teaching the English language within a context of Malaysian secondary schools.

\section{Method}

As a qualitative study involves a naturalistic and interpretive approach (Merriam 2009), the first step was to identify the context. As this study involved observations and very close interviews, the master teachers who were to from the cases had to come voluntarily. Hence, through a networking of friends, five master teachers were initially identified. As the research procedures were explained, access to the site of inquiry became a problem as the school authorities were not keen to be part of the study. Finally, the research was able to garner three female master teachers who volunteered as participants for the study.

\subsection{The Participants}

The three female teachers were Miss M, Miss R and Miss L and all three fulfilled the criteria for selection: they are all master teachers of the English language; have more than 15 years of teaching the subject; possess at least a degree and more importantly for the research, were willing to be observed, interviewed and grant access to teaching documents like lesson plans and teaching aids.

Miss M is a fifty year old Malay senior teacher in a premier school with a degree in ELS and 28 years of teaching experience. She has been teaching in the present school for 15 years and has been selected as one of the trainers of the district. She is a 'mentor' to novice teachers.

Miss $\mathrm{R}$ is forty three year old Malay, who has been teaching for 18 years. She graduated in TESL but due to her passion for literature, she studied for masters in literature in English. She has held administrative positions as 
head of the English language department.

Finally, Miss L is a forty five year old Indian with an interesting background. She graduated in Malay letters but trained in the teaching of English. As she felt the need to learn more about English, she enrolled in masters in ELS.

\subsection{The Procedures}

Once the permission from the gatekeeper (the School Principal) was obtained, classroom observations were planned, and due to many administrative (timetabling) and teaching constraints, three observations were scheduled per case study. In order to get 'a feel' of the site of enquiry, 'informal' observations of the schools were also conducted. The researcher also spoke to the teachers, students and the school administration to get an in-depth feel of the teaching of English language. Informal interviewing was conducted with both the teacher and the students usually after the lessons. Nevertheless, there were occasions when the teachers would be asked about the lesson plans and activities before the classes. At other times, the interviews were mere chats 'to see the person behind the teacher'. During observations, the researcher sat the back of the class to enable her to get a full view of the entire space and made it a point to be as unobtrusive as possible.

An observation protocol was also used to aid the researcher in the writing of the field notes. Merriam (2009) and Creswell (1998) had suggested the inclusion of comments and reflections in the field notes and this was duly complied. Special attention was given to the setting, the process in which the lesson was conducted, the strategies used by the teachers and their interactions with the students. Throughout the data collection period, the researchers were mindful of this being a humanistic enquiry with much at stake.

As it was not easy to go to the schools due to institutional constraints the observations took about four months to complete. The observations were audio recorded and transcribed. Field notes were also taken by the researcher. During this time the interviews were conducted and the documents were also collected and perused. Hence the primary data were from the observations (transcriptions and field notes) and triangulated with the interviews and documents. During the interviews, the teachers were asked about 2 key issues: background of teacher and the students (including their principle or philosophy in teaching, and the students' level of English as well as their attitude) and the day's lesson (objectives, strategies and challenges). Since the interview was not closely structured, the teachers spoke freely and in the process were able to reflect on themselves as a person as well as their best practices.

Once the data were collected, the process for data analysis followed a four-step procedure. Firstly, a case study data base for each master teacher was developed. This is followed by coding through a macro and micro analysis. Many qualitative researchers will agree that coding is a recursive process, and according to Merriam (2009) is the preliminary stage to theme construction. And from there, emergent themes will be identified. In this study, coding comes in two stages: open and focus. While open focuses on "....naming and categorizing of phenomena through examination of data" (Strauss and Corbin 1990, p. 62), focus coding is done to classify the codes into more specific categories. This was done for each case (within case analysis) which then led to cross case analysis In order to verify the data, triangulation process was carried out between the primary data (field notes and lesson transcriptions) to the interviews and documents.

\section{Results and Discussion}

In order to have an appreciation of the challenges faced by these master teachers, a description of the sites of enquiry is important. The three teachers come from two different schools. Miss $\mathrm{M}$ is in a co-educational secondary day school, while and Miss L and Miss R are in a secondary residential school. Miss M's students are Form Four students from a below average class. The two different types of schools as in the case in Malaysia have a bearing on the types of students. Day schools or neighborhood schools do not screen their student intake, but a residential school (as in the case of Miss L and Miss R) enrolls students based on a qualifying examination. Hence the students are generally better. Further, the students here are streamed according to their English proficiency, and so they do not have their English lessons in their respective classes but in a designated class.

As master teachers, the three case studies are similar in many ways - they are enthusiastic about teaching, they are approachable, comfortable to talk to and did not have any outward signs of being concerned about the being the focus of a research. They are also very adaptable as evidenced from the fact that they do not have a fixed classroom to teach English. The three teachers had to rotate their classes - with each master teacher having to shuttle between two classes. Nevertheless these experienced teachers took it all in their stride and were rather cheerful about it and attributing it to institutional constraints. 
On improving English proficiency, Miss M is of the opinion that her students' interest in reading and their reading skills need to be improved. This is not surprising as she is passionate reader and is very happy to head the Resource Room. In her school cubicle, there are many thank you and congratulatory cards neatly arranged on a soft board. She plans her own activities for her students, has led the writing of modules for the English classes and with a small team, she has also prepared the literature component for her students.

As Miss M is passionate about literature, she has turned literature classes into drama project, breathing life into the texts. She believes that drama is not only about being on-stage, but an activity that will boost the students' confidence and which allows opportunities for planned and incidental public speaking. Miss M constantly reviews her students' performance and one of her observations has led her to reflect on changing the approach to classroom practices. To cite an example, she noticed that reading-into-writing is a weakness of her students, and so she (at the time of the study) led an action research to improve on the writing skills of the students. As the Head of English panel, she would spend hours preparing materials not just for herself but for collective use, but she laments that at times this was not well received. In an interview she shares her principle in teaching, "The way to achieve work is through the mind, the way to reach people is through the heart."

Miss R also holds an administrative position, and it is observed that she is not as very forthcoming but she comes across as a good listener. In terms of materials production, Miss R, as in the case of Miss M also prepares her own materials for class. When interviewed she stated that it is more appropriate to develop her own materials as it creates a sense of expectation among her students and increases their motivation. In class, Miss R shows that she knows all her students, which is admirable because of the large size of Malaysian classrooms.

As her motto is "Practice makes perfect", Miss R has made it mandatory for her students to keep a journal that is submitted at the end of each week on Friday and returned on Monday. The journal entries are not decided for her and hence that freedom provides for a range of topics that are not covered by the syllabus. Students enjoy this and she in turn gets 'a peek' into the private lives of her students. She also makes it mandatory for students to take turns to give a spontaneous speech in front of the class before lessons.

Unlike Miss M and Miss R who have been assigned to rather better classes, Miss L has been assigned the last class in the form. Within the Malaysian school system, this class would be challenging even to the most experienced teacher. In this case, Miss L has she turned to technology to put fun into teaching. Like Miss M, she believes in improving the students' literacy (especially reading) but these weak students are rather inattentive and easily distracted. Hence, she chose to vary the medium and since this generation of students is more visually inclined. She worked hard to prepare slides and power points and encouraged them to seek and elicit information from the Internet for class work. Her motto is, "Learning is Fun."

In all three cases, the data showed that the master teachers have accepted the challenging situation and problematised them. As Loughran (2010) has intoned, once a teacher has accepted that teaching is 'problematic', it has to be managed well through responding to our students' needs and concerns at any one time. This was also evident in Tsui's (20030 studies where the 'expert' teachers problematised each teaching session and planned for every stage os the lesson. Hence, in both Loughran (2010) and Tsui (2003) teachers who are experts and masters will not adopt a 'one size fits all' approach. It is on this premise that the three teachers are ionvestigated and the following strategies of the master teachers have been uncovered.

\subsection{Teachers as Planners}

It is imperative that a teacher must make proper planning prior to going to class. Butt (2006, p.2) offers this insight:

The key to good teaching, purposeful class management and the achievement of sustained educational progress lies in effective planning. Learning does not occur by chance. Therefore it is very rare for a 'good lesson" to result from a teacher entering the classroom unprepared, without any procedure of the lesson being clearly planned beforehand.

Hence teachers need to make the necessary planning before entering the classroom. Being unprepared would result in poor and unsatisfactory lessons. In this respect, all three teachers were found to have planned their lessons ahead of their classes as reflected in the teaching materials collected and perused. Miss $\mathrm{m}$ had prepared power point slides which were sequenced according to the flow of her lessons. Miss R and miss L on the other hand, had prepared task sheets to sequence the lessons. 
Apart from that, the data from the classroom discourse also revealed how all three teachers began each lesson with an induction set to engage the students. Here Miss M employed a breathing activity, Miss R engaged her students by playing a song and Miss L showed an advertisement on the LCD projector. Hence these choreographed set inductions were carefully planned to set the tone of the lesson.

The set inductions were then followed by supporting tasks leading to the desired goals of the lessons. These pre set activities functioned as scaffoldings to the actual lessons. For example, the following diagram demonstrates Miss M's support activities that were aimed to ease the students into the actual drama event.

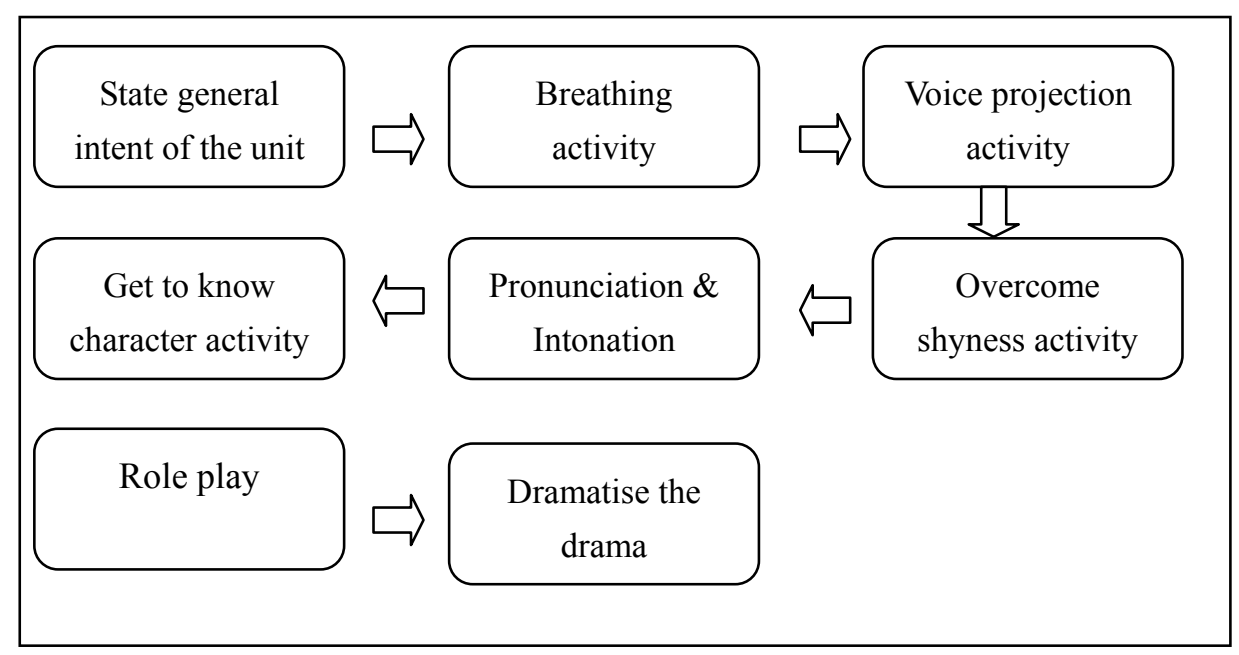

Figure 1. Miss M's support activities

One note that the activities that Miss M had incorporated in Figure 1 were employed to gently ease the students into the dramatization of "Of Gulp and Gasp'. The unit as shown in the diagram comprised of three lessons. To engage the students, Miss M provided the metastatement of the unit in the first lesson followed by breathing and voice projection activities. As the students are relatively reserved she continued with overcome shyness activity and then ended the lesson with pronunciation and intonation. In the second lesson, the students get to know the characters and did serious role play. They rehearsed and got ready for the dramatization carried out in the third and final lesson of the unit.

At this point, the data also showed that a master teacher who has planned her lessons or unit should also be ready to abandon her original plan and replace it with a contingency plan. In Miss M's second lesson she had focused on adjectives to describe the characters in the drama. However, at the end of the lesson she realized that she still had a few more minutes before the next lesson and so she asked the student to give antonyms to the adjectives taught although that was not part of the lesson plan.

\subsection{Teachers as Facilitators}

It is imperative that teachers should facilitate learning and in this respect, the master teachers employed elicitation techniques to this end. Mercer (2001) asserts that elicitations could be used to draw response from the learners and this would facilitate learning. Van Lier (1988) suggests that elicitation in the classroom may comprise display and referential questions. He contends that display questions refer to questions in which the teacher already knows the answer while referential questions are those where the answers are not known to the teacher in advance. Van Lier asserts that referential questions are genuine information questions.

The classroom data show that all three teachers employed both types of questions in varying degrees. Miss $M$ for instance, was found to have used more display questions as compared to the othe two teachers. A sample of the data is shown below: 
Table 1. Extract 1: Miss M's lesson

\begin{tabular}{lll}
\hline 311 & T & Alright, it's gorilla. What were they doing? \\
\hline 312 & LL & Fighting \\
313 & T & Fighting for what? Do you know? \\
314 & LL & For friends \\
315 & T & For mates. MATES. For mates. Alright. And a:: what else, you tell me. You watch. \\
316 & LL & Fighting with each other \\
317 & T & Fighting with each other, next? \\
318 & LL & The king kong lose \\
319 & T & The king kong? \\
\hline
\end{tabular}

The data showed that Miss M wanted the students to describe the scen the classmates had perfomed. The initiation "What were they doing" was meant to elicit a longer response but a one word choral response (Fighting) was offered. Hence the teacher's untterances in lines 313, 315 and 317 were employed to elicit longer responses.

In the case of Miss R, it is noted that she used more referential questions than display questions in her discourse. This is in contrast to Long and Sato (1983) and Rosniah Mustafa et al. (2009) who claim that ESL teachers use less referential qustions in their elicitations. Extract 2 below illustrate this point.

Table 2. Extract 2: Miss R's lesson

\begin{tabular}{|c|c|c|}
\hline 034 & $\mathrm{~T}$ & $\begin{array}{l}\text { I know you have not seen this. Ok. If you have seen the headline of the report, ok? } \\
\text { What would come to your mind? }\end{array}$ \\
\hline 035 & $\mathrm{~F}$ & Some a:: girl missing \\
\hline 036 & M & I marry the girl \\
\hline 037 & $\mathrm{~T}$ & $\begin{array}{l}\text { Huh? You marry the girl }(0.5) \text { ok, huh Hazim. If you see this headline erm what is the } \\
\text { news that is to be reported? }\end{array}$ \\
\hline 038 & $\mathrm{H}$ & A daughter who runs away \\
\hline 039 & $\mathrm{~T}$ & A daughter who runs away. What do you girls think? \\
\hline 040 & $\mathrm{~N}$ & A:: daughter being \\
\hline 041 & $\mathrm{~F}$ & Kidnapped \\
\hline 042 & $\mathrm{~T}$ & Kidnapped. Ok. What else? \\
\hline
\end{tabular}

The exchanges above show how referential questions are posed after certain responses. This was in response to a newspaper report entitled, "Come Home my Dear Daughter" that was brought to the class by the teacher. The referential questions posed were used as catalyst to engage the students and to make them think outside the contents of the newspapers. In the above extract, several students were rather active but by nominating one (Hazim) the teacher was able to allow for greater participation. But the second student who responded (036) seemed to give the wrong answer which resulted in the teacher rephrasing the question in 037. This was rewarded with Hatim's more appropriate answer in 039 and a feedback by way of a repetition in 039 . The referential question then followed that was posed to inquire into whether 038 were correct or otherwise.

What is crucial about Miss R's lesson is the way she encouraged her students to follow the exchanges and then to weigh the responses. In so doing and by way of nominating students, Miss R was able to keep the students engaged in the lesson.

\subsection{Teachers as Role Models}

A rather important insight into the classroom discourse of all three teachers is the effort they put in to use English in the classroom. As mentioned earlier, the main challenge of teaching English in Malaysian schools is the status of the language within the curriculum. It is language to be learnt but it is not necessary to pass. Hence not many students are motivated to do well in the language. Code switching and code mixing are very common.

Where Miss R is concerned she believed that she has to use Standard English as her students' actual contact with the language is minimal. In one of the interviews she said 
They only speak during English lessons so the objective of me speaking English most of the time is so that they would listen to better pronunciation than them, to ask them to listen to phrases and vocabulary that they would be using in their writing,

This view was also mooted by the other two master teachers who claimed that they tried their best to use Standard English most of the time so that the students could attempt to emulate them. In this respect Pillay (2004) argues for Standard English that is internationally intelligible to be the variety adopted by Malaysian teachers.

As role models, both Miss R and Miss L allow for errors in language and do not carry out direct corrections on students' mistakes. They believe that communication must take place for language learning to happen and must not be hampered by interruptions. To them correcting errors openly would only discourage the students. This view is in line with Walsh (2006) who maintains that students' speech might be hampered if teachers are to repair each and every error committed by students. However, Miss $M$ believes that in learning a language, students should be taught the system first and then when errors are committed, they should be corrected immediately. Such immediacy is to her crucial as it will prevent the students from forgetting that an error has been committed. Her classroom discourse is seen to be peppered with incidental correcting. Indeed, a teacher's belief of how language is to be learnt shapes her classroom discourse (Hampton 1994).

\subsection{Teachers as Materials Developers}

As these master teachers plan their lessons to facilitate their students learning process, they have indeed discovered that not all the materials from the ministry are appropriate for use. Hence all three of them design and develop materials which are not for their own use but also for their colleagues. Findings from the informal conversations and interviews reveal that these teachers design the materials in accordance to the aims of the lessons, their students' level of proficiency as well as the students' interests. As such, the materials are tailor made for the students. To further engage the students, Miss L said;

They were just back from celebrating National Day so I just chose something that I think the students like, what is current. If you want them to talk about old issues, you cannot get them, grasp their attention. What is current and what is latest they like, so that is one way. Even if you wanted to choose a topic or lesson it has to be something that is contemporary. They will somehow be attracted to the lesson.

It is obvious that Miss L takes the trouble to reflect on what the students like and dislike, and what may interest them so that they will be engaged in the lessons. Such an act by Miss L is reminiscent of what Armstrong et al. (2001) has reminded teachers to pay special attention to what motivates students when identifying and selecting the content of materials.

The teachers opine that while they keep in mind the aims and objectives of the curriculum, they should exercise their discretion in developing meaningful materials that will promote learning. Miss M's pre dramatization activities, like breathing and intonation for instance are not in the standard exercises as provided for by the ministry but have been developed by her when she noticed her students' weaknesses. Miss R and Miss L who are passionate about incorporating ICT into their lessons have been rather disappointed not to be able to do so as the designated classrooms do not have connectivity. Nevertheless they produced their lesson kits using audio visuals (stills).

\section{Conclusion}

This paper has presented what master teachers do in order to provide for a successful learning environment for the teaching of English language. The data have shown how challenging the task is, with the absence of a permanent physical setting as well as the status of the subject itself. Hence it is comforting to note that despite the challenges these three master teachers have raised to the fore. The interest and dedication they have displayed in employing the various strategies to engage the studies have shown that they are indeed, master teachers, true to their calling.

\section{Acknowledgements}

This paper was made possible with the assistance of research grant UKM-PTS-029-2-12.

\section{References}

Armstrong, D. G. et al. (2001). Teaching Today: An Introduction to Education. New Jersey; Merill prentice Hall.

Atkinson, D., Okada, H., \& Talmy, S. (2011). Ethnography and discourse analysis. In K. Hyland, \& B. Paltridge (Eds.), Continuum companion to discourse analysis (pp. 85-100). London: Continuum.

Butt, G. (2006). Lesson Planning (2nd Ed.). New York: Continuum .

Coladarci, T. (1991). Effective Teachers and Research on Teacher Effectiveness: The Relevance of Educational 
Research for Identifying Master Teachers. Occasional Paper Series No. 1. Maine University College of Education.

Creswell, J. W. (1998). Qualitative Inquiry and Research Design: Choosing among the traditions. Thousand Oaks: Sage Publications.

Creswell, J, W. (2008). Educational Research: Panning, Conducting and evaluating Quantitative and Qualitative Research (3rd ed). New Jersey: Pearson.

Denzin, N. K. (1978). The research act. New York: Mc-Graw Hill.

Dreyfus, H. L., \& Dreyfus, S. E. (1986). Mind over Machine: The power of human intuition and expertise in the age of the computer, Oxford, Basil Blackwell.

Ericsson, K. A. (2002). Attaining Excellence through Deliberate Practice: Insights from the Study of Expert Performance. In M. Ferrari (Ed.), The Pursuit of Excellence Through Education (pp. 21-56). Mahwah, NJ: Lawrence Erlbaum Associates.

Geertz. C. (1973). The Interpretation of Cultures: Selected Essays. New York: Basic Books.

Genzuk, M. (2003). A Synthesis of Ethnographic Research. Occasional Papers Series. Center for Multilingual, Multicultural Research (Eds.), Center for Multilingual, Multicultural Research, Rossier School of Education, University of Southern California. Los Angeles.

Hampton, S. (1994). Teacher Change: Overthrowing the Myth of One Teacher One Classroom. In T. Shanahan (Ed.), Teacher's Thinking, Teacher's Knowing. Illinois: NCRE 122-140.

Hapidah Mohamed. (2001). Pemikiran Guru Cemerlang: Kesan Terhadap Prestasi pengajaran. UnPub. PhD Thesis. Universiti Kebangsaan Malaysia.

Loughran, J. (2010). What expert teachers do: Teachers' professional knowledge of classroom practice. Sydney: Allen \& Unwin and London: Routledge.

Lincoln, Y., \& Guba, E. (1985). Naturalistic Inquiry. Beverley Hills, CA: Sage.

Malaysia Education Blueprint 2013-2025.

Mercer, N. (2001). Language for teaching a language. In Candlin, C. N., \& Mercer, N. (Eds.), English Language Teaching in a Social Context: A Reader. New York: Routledge.

Merriam, S. B. (2009). Qualitative Research: A Guide to Design and implementation. San Francisco. Jossey-Bass.

Mohd. Sahandari, \& Gani Hamzah, et.al. (2008). Excellent Teachers' Thinking Model: Implications for Effective Teaching. Australian Journal of Teacher education, 33(4), 11-27.

Ng Soo Boon. (2009). Implementation of the revised Secondary School Curriculum by Master teachers in Creating a Thoughtful Classroom. UnPub. PhD. Thesis. Faculty of Education, University of Malaya.

Pillay, H. (2004). Muddied Waters: The issue of Models of English for Malaysian Schools. Paper presented at MICELT, Malaysia.

Rahayu Johari. (2009). Pengaruh Gaya Pengajaran guru Cemerlang Fizik terhadap Gaya Pembelajaran dan Pencapaian Matapelajaran Fizik Pelajar Tingkatan Empat. UnPub. Master thesis. Universiti Kebangsaan Malaysia

Saran Kaur Gill, Radha Nambiar, Noraini Ibrahim, \& Tan Kim Hua (2011). Globalization and Language-in-Education Policy Shift in Malaysia: Challenges of Implementation. Globalization of Language and Culture in Asia: The Impact of Globalization Processes in Asia (pp. 180-205). Vaniti Vaish (ed.). Singapore: Continuum.

Tsui, B. M. Amy. (2003). Understanding Expertise in Teaching. Cambridge: Cambridge University Press.

Walsh, S. (2006). Investigating Classroom Discourse. London: Routledge Taylor and Francis Group.

Van Lier, L. (1988). The Classroom and the Language Teacher: Ethnography and Second Language Classroom Research. London: Longman. 